\title{
LC-MS/MS Method in Nicotine Metabolites Quantification
}

\section{ADRIANA GHERBON ${ }^{1}$, MIRELA FRANDES ${ }^{2 *}$, LAVINIA NOVEANU ${ }^{3}$, MARIOARA NICULA ${ }^{4}$, DOREL DRONCA ${ }^{4}$, MIRELA AHMADI $^{5}$, MIHAI IONITA ${ }^{6}$, ROMULUS TIMAR ${ }^{1}$}

${ }^{1}$ Victor Babes University of Medicine and Pharmacy, Faculty of Medicine, $2^{\text {nd }}$ Department of Internal Medicine, Discipline of Diabetes, Nutrition and Metabolic Diseases, 2 Eftimie Murgu Sq., 300041, Timisoara, Romania

${ }^{2}$ Victor Babes University of Medicine and Pharmacy, Faculty of Medicine, Department of Biostatistics and Medical Informatics, 2 Eftimie Murgu Sq., 300041, Timisoara, Romania

${ }^{3}$ Victor Babes University of Medicine and Pharmacy, Faculty of Medicine, Department of Pathophysiology, 2 Eftimie Murgu Sq., 300041, Timisoara, Romania

${ }^{4}$ King Mihai I of Romania Banat University of Agricultural Sciences and Veterinary Medicine, Faculty of Bioengineering of Animal Resources, 119 Calea Aradului, Timisoara, Romania

${ }^{5}$ King Mihai I of Romania Banat University of Agricultural Sciences and Veterinary Medicine, Faculty of Veterinary Medicine, 119 Calea Aradului, Timisoara, Romania

${ }^{6}$ Victor Babes University of Medicine and Pharmacy, Faculty of Medicine, $1^{\text {st }}$ Department of Internal Medicine, 2 Eftimie Murgu Sq., 300041, Timisoara, Romania

Abstract. Nicotine is a ganglioplegic alkaloid, being the main component of tobacco. Some of the final metabolites of nicotine could be used to evaluate the nicotine dependency in humans using the Fagerström test. The test consists in cotinine quantitative determination, and evaluation of the correlation between cotinine from plasma and from urine. Cotinine quantification was performed using LC-MS/MS method both for blood and urine, in a private authorized laboratory for medical tests. Our study was conducted in two stages $\left(1^{\text {st }}\right.$ year of study - initial assessment; and $6^{\text {th }}$ year of study - final assessment) and included 62 apparently healthy subjects (77\% females and $23 \%$ males) with an average age of $19 \pm 1.48$ years at baseline, respectively $24 \pm 0.83$ years at the final assessment. The prevalence of smoking increased significantly from $14.51 \%$ to $32.25 \%(p=0.01)(11 \% \mathrm{~F}$ and $3 \% \mathrm{M}$ initially, respectively $25 \% \mathrm{~F}$ and $7 \% \mathrm{M}$ final). The final assessment found that $21 \%$ became smokers after starting their university studies, $11 \%$ were permanent smokers throughout the $6^{\text {th }}$ year study, and only $3.22 \%$ quit smoking. Percentage distribution on smoking addiction levels was at baseline: mild 11\%, moderate $33 \%$, severe $56 \%$, and a final assessment: mild $15 \%(p=0.77)$, moderate $75 \%(p=0.01)$ and severe $10 \%$ ( $p=0.007)$. The results show a significant increase in the number of smoker girls compared to boys, $a$ significant increase in the prevalence of moderately dependent smokers and a significant decrease in the prevalence of severely dependent smokers. LC-MS/MS can be used very well to evaluate the cotinine content in blood and urine, which could be used in Fagerström test in order to evaluate the nicotine addiction in young people and to find priority solutions for smoking prevention and quit smoking.

Keywords: nicotine, metabolism, smokers

\section{Introduction}

Nicotine is a ganglioplegic alkaloid, found in plants, having in its chemical structure a pyridine ring linked to a pyrrolidine ring. It is the main component of tobacco (different species of Nicotiana, of the Solanaceae family, of which the most important are Nicotiana tabacum and Nicotiana rustica, both cultivated), but it can be found also in other plants (some Lycopodium species), but always in small quantities - according to data presented by Domino and his collaborators, cited by Karaconji [1].

In humans, the nicotine acts as an addictive central nervous system stimulant, which in high doses produces ganglionic blockage and in low doses produces ganglionic stimulation. In low concentrations (about $1 \mathrm{mg}$ of absorbed nicotine), nicotine acts as a stimulant in mammals and is the main factor responsible for addiction. Volkow in 2011 found that nicotine inhibits enzyme-chromatin (class I and II histone deacetylase), which increases the ability of cocaine to cause addiction [2].

\footnotetext{
*email:mirela.frandes@umft.ro
} 
Over the years, nicotine content in cigarettes has slowly increased for all major categories of cigarette [3].

Nicotine absorption is depending on the $\mathrm{pH}$, which influence the speed, quantity, and also the chemical derivate of nicotine, but the buccal absorption is not significant. Once that nicotine is absorbed, it reaches the bloodstream, and at $\mathrm{pH} 7.4$ about $69 \%$ becomes ionized, and $31 \%$ un-ionized, while less than $5 \%$ becomes binds to plasma proteins. The metabolic pathway of nicotine starts in liver with the nicotine transformation under the action of main specific enzymes: UDP-glucoronosyl-transferase (UGT), CYP2A6, and flavin-containing-mono-oxygenase (FMO), which leads to many final metabolites. But the main important final metabolite of nicotine metabolism is cotinine. The metabolic process happened in two steps: the first one produces nicotine- $\Delta^{1^{\prime}\left(5^{\prime}\right)}$-iminium ion - which is catalyzed by an aldehyde oxidase enzyme in the cytoplasmic environment. Another important chemical compound formed in the metabolic pathway of nicotine is catalyzed by flavin-containing-monooxygenase with the formation of nicotine N'-oxide - which is very important because the trans-isomer can be detected in urine smokers. In humans, from the total intake of nicotine only about $70-80 \%$ is metabolized via cotinine pathway, and from this quantity only about 10 to $15 \%$ appears as cotinine in urine. To evaluate the nicotine absorption in patients there is used the rate of nicotine and cotinine metabolism. Thus, it is important to mention that the nicotine total clearance in about $1200 \mathrm{ml} / \mathrm{min}$, while the cotinine clearance is about $45 \mathrm{ml} / \mathrm{min}$ - being much slower than the nicotine clearance $[4,5]$.

LC-MS/MS method could be a very useful test to evaluate the concentration of some nicotine metabolites, like cotinine - which can be used in evaluation the nicotine addiction and also to evaluate the CYP2A6 role in nicotine metabolism pathways and the oxidative stress due to the smoking habits $[6,7]$.

Nicotine, irrespective of the route of administration, penetrates the body through diffusion, inhaled smoke reaches the lungs, and all constituents are absorbed. $80 \%$ of nicotine is destroyed at the liver and the remaining $20 \%$ is fixed to nicotinic receptors through which it exerts its multiple effects [3].

The Fagerström test is used to measure nicotine dependence; the test has the advantage of showing an exact correlation between test responses and plasma and urinary nicotine [8].

Generally, there are three types of nicotine addiction, namely, behavioral and social addiction (occasionally in certain moments of workday: the so-called "cigarette to coffee"), psychological dependence (the smoker is unconsciously tempted to start a new cigarette to retrieve memory of pleasure sensations), and physical dependence that begins only after a few years (chronic smokers smoke to avoid feelings of nervousness, irritability, concentration disturbance) [9].

A percentage of $20 \%$ of smokers want to quit, but they can't do it easily; specific anti-Tabac treatments can give results to some people, while some not. No drug can suppress the craving to smoke, but there are nicotinic substitutes that help eliminate smoking during the initial withdrawal phase [10].

\section{Material and method}

The study was performed on 62 healthy subjects, of which $77 \%(n=48)$ were females and $23 \%(n=14)$ male, with an average of $19 \pm 1.48$ years at baseline, respectively $24 \pm 0.83$ years in the final assessment.

Subjects were selected based on the voluntary Fagerström test completion through was assess the degree of nicotine addiction in smokers, using the LC-MS/MS method to analyzed the concentration of cotinine in blood serum and urine from an authorized laboratory for medical $[4,8]$. The HPLC and mass spectrometry (LC-MS/MS) method is used for quantitative analysis of nicotine, cotinine and also nitrosamine ketone.

The study was conducted in two stages: 1 st year of study- initial assessment; $6^{\text {th }}$ year of study- final assessment.

The questionnaire was validated by the Ethics Committee of the Victor Babes University of Medicine and Pharmacy Timisoara. Each subject signed an informed consent form through which it received data on the objectives of the study, the methods used, the benefits and risks of the study and the confidentiality of the results. 
We measured the quantitative level of cotinine in the blood and urine. Cotinine is one of the main metabolites of nicotine, but it is used in evaluation of nicotine dependency. Exposure to tobacco smoke in the environment can be estimated based on the levels of cotinine in the blood or urine. Cotinine levels correlate very well with the value of exposure to tobacco smoke, including passive smoking.

The measured data were statistically processed using IBM SPSS Statistics v.20 software. The central trends of the variables obtained from $n$ subjects were expressed as mean and the dispersion as standard deviation. When comparing the means from two groups, the t-Student test or Mann-Whitney U test was used, when appropriate. For all the applied tests, we considered a result statistically significant when $p$ value $<0.05$.

\section{Results and discussions}

The prevalence of smoking increased significantly from $14.51 \%(n=9)$ to $32.25 \%(n=20)(p=0.01)$. In the initial evaluation, $11 \%(\mathrm{n}=7)$ of smokers were feminine gender subjects and $3 \%(\mathrm{n}=2)$ were masculine gender $(p=0.01)$. In the final evaluation, $25 \%(\mathrm{n}=16)$ of smokers were feminine gender subjects and 7\% $(\mathrm{n}=4)(p<0.001)$ were masculine gender (Figure 1).

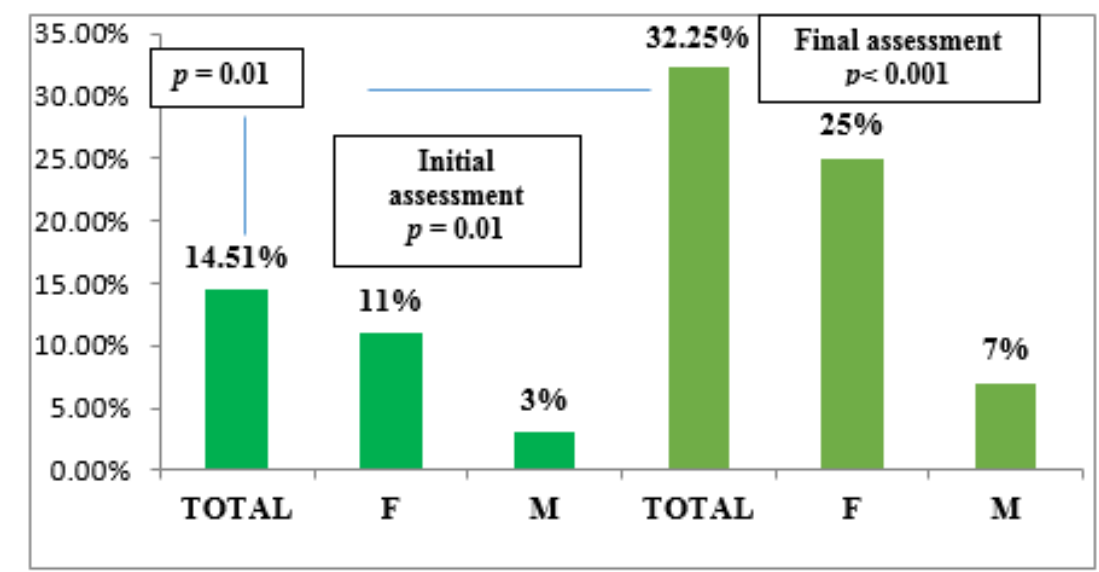

Figure 1. Comparative gender distribution of smoking

Prevalence in initial and final assessment

In Romania, the prevalence of smoking is $28 \%$ for people over 15 years old, close to the European average (26\%). The percentage of young smokers (aged 15-24) increased from $25 \%$ in 2014 to $29 \%$ in 2017 [11].

A study carried out in Romania on medical students in the first and third year of study at the Victor Babes University of Medicine, and Pharmacy Timisoara showed an increasing tendency of smoking prevalence among them, with a trend to gender equality in the third year of study [12].

In Romania, among men, the smoking prevalence is 38\%, and among women 19\% [13].

Compared to the total number of subjects included in the final evaluation, $21 \%(n=13)$ became smokers after starting studies, $11 \%(\mathrm{n}=7)$ were permanent smokers throughout the six years of study, and only $3.22 \%(\mathrm{n}=2)$ quit smoking (Figure 2).

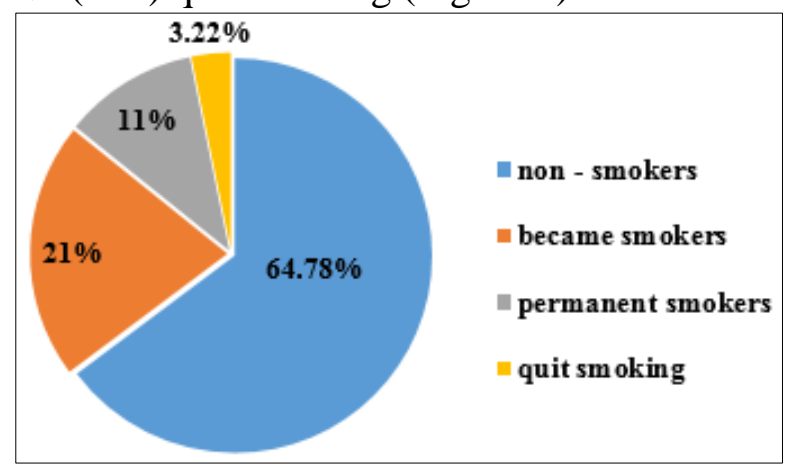

Figure 2. Distribution of subjects by smoker status at the final assessment 
From the category of smokers that became smokers after starting studies, $85 \%(n=11)$ were girls and $15 \%$ were boys $(\mathrm{n}=2)(\mathrm{p}<0.001)$. From the category of subjects who were permanent smokers, over the 6 years of study, $71 \%(n=5)$ were girls and $29 \%(n=2)$ were boys $(p=0.04)$ (Figure 3$)$. We mention that in the smoking cessation category, all were feminine gender subjects.

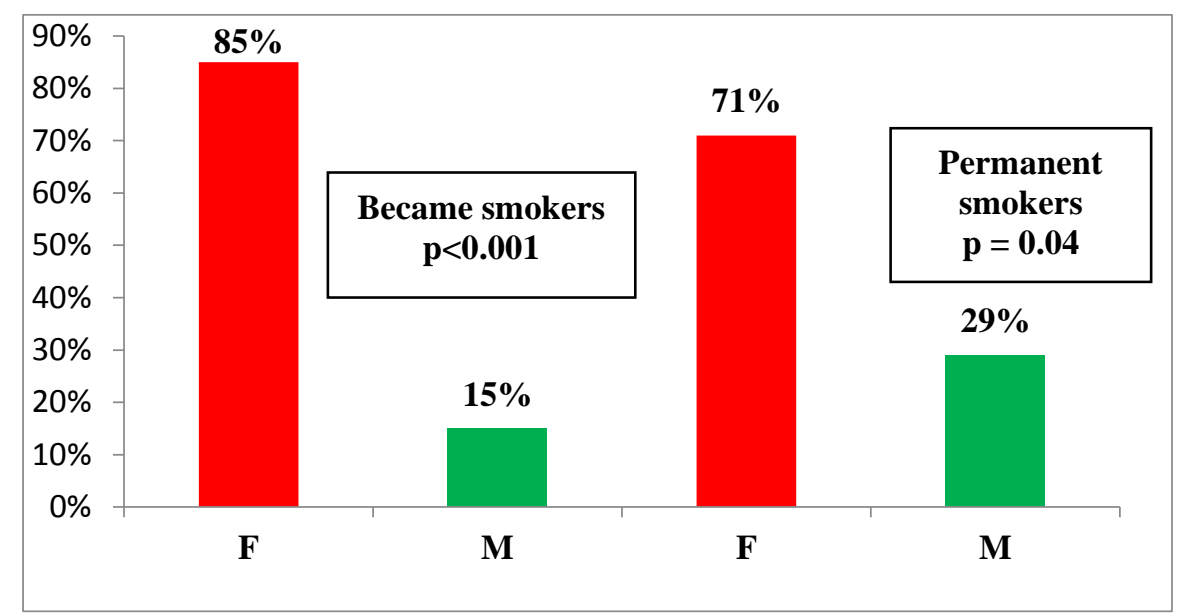

Figure 3. The prevalence of smoking categories by gender, at the final assessment

Relative to the total number of feminine gender subjects $(n=48), 32 \%(n=16)$ became smokers, $10 \%$ $(n=5)$ continued to smoke during the 6-year study and 3\% (n=2) quit smoking (Figure 4). Thus, compared to the initial situation in which $14.58 \%(n=7)$ of the girls were smokers, at the end of the medical studies the percentage of smokers increased statistically significantly to $32 \%(n=16)(p=0.01)$ (Figure 5).

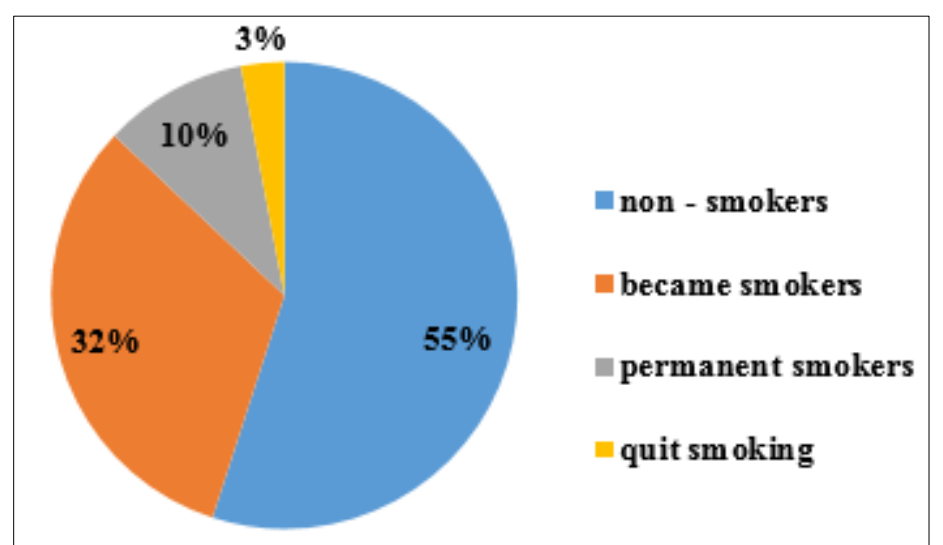

Figure 4. Distribution of feminine gender subjects by smoker status at the final assessment

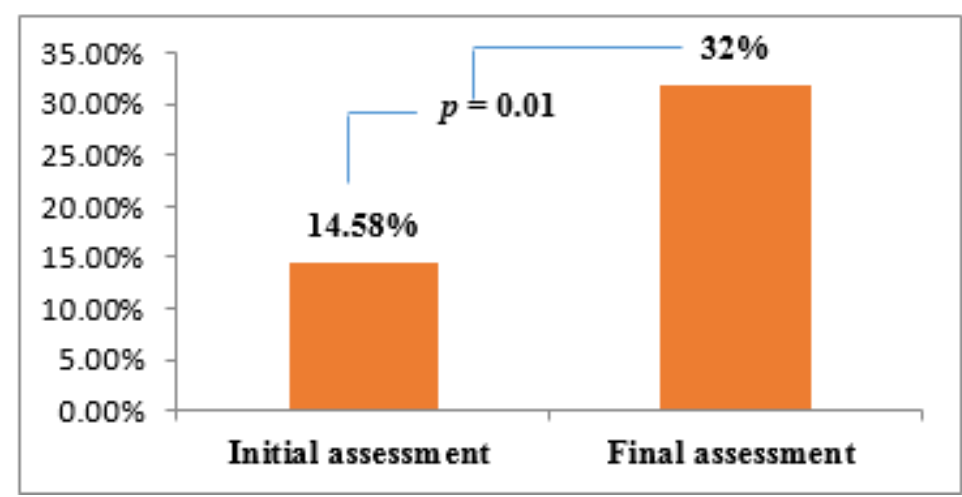

Figure 5. Evolution of smoking prevalence in feminine gender subjects 
Relative to the total number of masculine gender subjects $(n=14), 14 \%(n=2)$ became smokers, and a similar percentage of $14 \%(n=2)$ were permanent smokers throughout the six years of study (Figure $6)$. In comparison to the initial assessment, where $14 \%(n=2)$ of the boys were smokers, the percentage of smokers increased insignificantly to $21 \%(n=3)(p=0.62)$ (Figure 6).

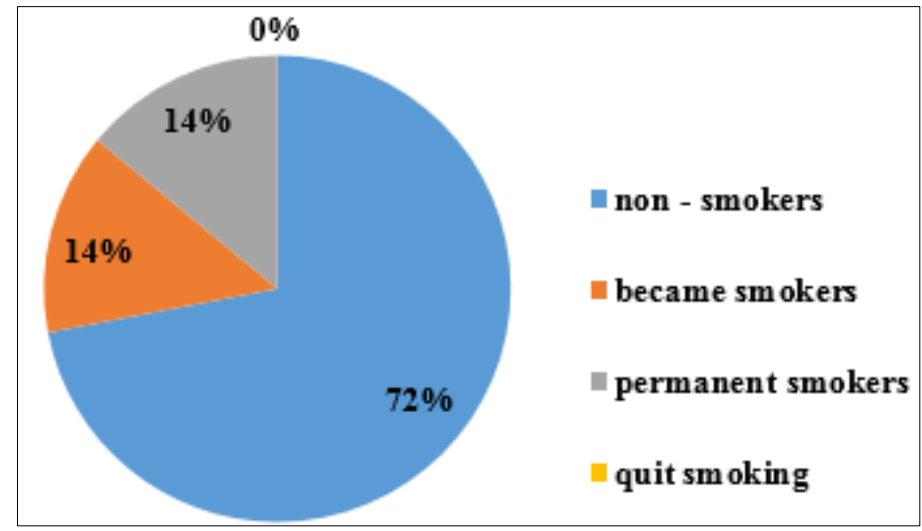

Figure 6. Distribution of male subjects by smoker status at the final assessment

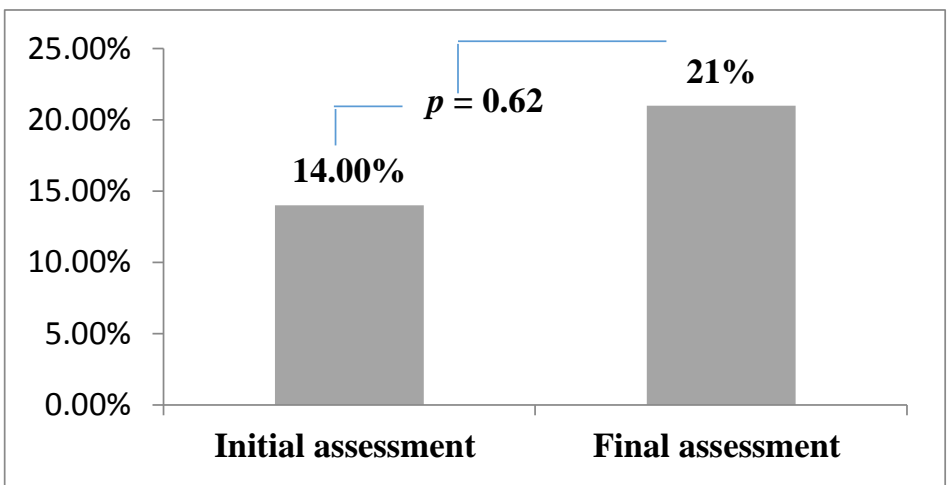

Figure 7. Evolution of smoking prevalence in male subjects

According to the Global Adult Tobacco Survey conducted in Romania (GATS 2011), the current prevalence of smoking is $26.7 \%$ (4.85 million inhabitants). Prevalence is higher among males than among women: $37.4 \%$ versus $16.7 \%$; $24.3 \%$ smoke daily: $34.9 \%$ of men and $14.5 \%$ of women, and $2.4 \%$ are occasional smokers: $2.5 \%$ of men and $2.2 \%$ of women $[14,15]$.

Among men, the lowest prevalence is reported by those with higher education (36.4\%), while among women the prevalence was higher among those with secondary or higher education $(19.6 \%$ and $20 \%)$ and minimal among women with elementary studies $(14.7 \%)[14,15]$.

The European School Survey on Alcohol and Other Drugs (ESPAD - 2015) shows that half (51.7\%) of 16-year-old pupils in Romania smoked at least once a year, about one-third $(30.1 \%)$ smoked in the last month and one from five smoked daily (19.8\%). Adult tobacco use has decreased since 2003 from $64 \%$, to 54\% in 2007 and 52\% in 2011, with maintaining the same value in 2015 (51.7\%). In 2015, was observed higher prevalence rates of tobacco use among boys up to the age of 16 compared with girls (52.8\% vs. 50.5\%), above the European average: $47.3 \%$ for boys and $43.9 \%$ for girls [16].

Daily smoking among boys in Romania has a prevalence of $21.3 \%$, and among girls $18.3 \%$, being for both genders also above the European averages: $13.4 \%$ for boys and $11.5 \%$ for girls. The study also found that about $23 \%$ of adolescents smoked the first cigarette before they reached the age of 14 [15, $16]$.

In terms of smoking addiction (Table 1), it was at the initial assessment of $6 \pm 2.50$ points, significantly higher $(p=0.002)$ compared to the final value of $4 \pm 1.55$ points. Prevalence on smoking addiction levels 
was at baseline: mild $11 \%(\mathrm{n}=1)$, moderate $33 \%(\mathrm{n}=3)$ and severe $56 \%(\mathrm{n}=5)$, and in the final assessment: mild 15\% $(\mathrm{n}=3)(p=0.77)$, moderate $75 \%(\mathrm{n}=15)(p=0.01)$ and severe $10 \%(\mathrm{n}=2)(p=0.007)$ (Figure 8).

Table 1. Criteria for interpretation

of the Fagerström score

\begin{tabular}{|l|l|}
\hline Degree of dependency & Number points \\
\hline Reduced & $0-2$ \\
\hline Moderate & $3-5$ \\
\hline Severe & $6-10$ \\
\hline
\end{tabular}

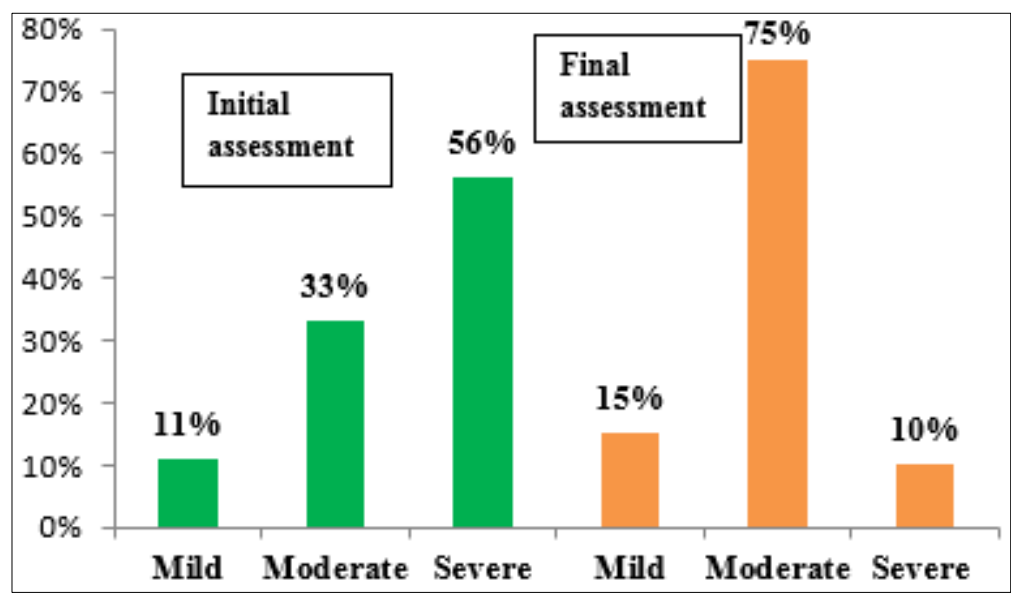

Figure 8. Distribution of severity of nicotine dependence, at the initial and final assessment

Concerning smoking cessation, $35.5 \%$ of current and ex-smokers have attempted to give up over the last 12 months [11].

Since the mortality rate was found to be $70 \%$ higher in smokers than in non-smokers, especially in younger age [17], the primary smoking-related diseases being the occurrence of bronchopulmonary cancer, obstructive pulmonary disease, coronary heart disease $[18,19]$, colorectal cancer. The presence of all these risk factors requires periodical participation in screening programs [20].

Nicotine has effects on the nervous system, causing addiction and disturbance of attention, memory, behavior [21], a series of strategies have been initiated in Romania to reduce tobacco consumption to a minimum, i.e., $5 \%$ of the adult population [11].

For Romania to reduce tobacco consumption with $30 \%$ by 2025 compared to 2010, the current (daily and occasional) smoking prevalence must reach $21.8 \%$ in 2025 , and daily smoking - to $18.4 \%$ of the population over 15 [11].

\section{Conclusions}

The LC-MS/MS is a useful method that can be used to evaluate the concentration of cotinine from blood serum and urine. The rate of quantified cotinine from plasma and urine allows to evaluate the smoking addiction in the experimental population.

Our experimental results show a significant increase in the number of girls who became smokers compared to boys who have not significantly altered their smoking status; a significant increase in the prevalence of moderately dependent smokers; and a significant decrease in the incidence of severely addicted smokers.

Exposure to cigarette smoke is harmful to people of all ages, but children and adolescents are a particularly vulnerable group to both short-term and long-term effects. Moreover, childhood and adolescence are periods of increased risk for smoking. 
Because nicotine addiction is rapidly becoming available to young people, specialists should action with priority in smoking prevention and take position during informative meetings.

\section{References}

1. KARACONJI, I.B., facts about nicotine toxicity, Arh. Hig. Rada Toksikol., 56, 2005, 363-371.

2. VOLKOW, N.D., Epigenetics of Nicotine: Another Nail in the Coughing. Science Translational Medicine, 3(107), 2011, 107, ps43. doi: 10.1126/scitranslmed.3003278.

3. BENOWITZ, N.L., HUKKANEN, J., JACOB, P., Nicotine chemistry, metabolism, kinetics and biomarkers, Handb Exp Pharmacol, 192, 2009, 29-60. doi: 10.1007/978-3-540-69248-5_2.

4. PEZZUTO, A., RICCI, A., BORRO, M., GUERRINI, S., GUERRINI, G., LIONETTO, L., The influence of nicotine metabolism rate and smoking habits on copd development: a retrospective study, Chest, 157(6), 2020, A440. doi.org/10.1016/j.chest.2020.05.498

5. CONNOLLY, G.N., ALPERT, H.R., WAYNE, G.F., KOH, H., Trends in nicotine yield in smoke and its relationship with design characteristics among popular US cigarette brands, 1997-2005. Tobacco Control, 16(5): 2007, e5. doi:10.1136/tc.2006.019695.

6. JIN, M., EARLA, R., SHAH, A., EARLA, R.L., GUPTE, R., MITRA, A.K., KUMAR, A., KUMAR, S., A LC-MS/MS method for concurrent determination of nicotine metabolites and role of CYP2A6 in nicotine metabolism in U937 macrophages: implications in oxidative stress in HIV + smokers, J. Neuroimmune Pharmacol., 7, 2012, 289-299.doi 10.1007/s11481-011-9283-6.

7. ABDALLAH, I.A., HAMMELL, D.C., STINCHCOMB, A., HASSAN, H., A fully validated LCMS/MS method for simultaneous determination of nicotine and its metabolite cotinine in human serum and its application to a pharmacokinetic study after using nicotine transdermal delivery systems with standard heat application in adult smokers, J Chromatogr B Analyt Technol Biomed Life Sci., 1020(5), 2016, 67-77.doi: 10.1016/j.ichromb.2016.03.020

8. PROKHOROV, A.V., PALlONEN, U.E., FAVA, J.L., DING, L., NIAURA, R., Measuring nicotine dependence among high-risk adolescent smokers. Addictive Behaviors, 1996; 21(1):117-127.

9. MIYASATO, K., Psychiatric and psychological features of nicotine dependence. Nihon Rinsho. Japanese Journal of Clinical Medicine, 2013; 71(3):477-81.

10. ROSEN, L.J., GALILI, T., KOTT, J., GOODMAN, M., FREEDMAN, L.S., Diminishing benefit of smoking cessation medications during the first year: a meta-analysis of randomized controlled trials. Addiction, 2018; 113(5):805-16. doi:10.1111/add.14134.

11. ${ }^{* * * h t t p: / / i n s p . g o v . r o / s i t e s / c n e p s s / w p-c o n t e n t / u p l o a d s / 2018 / 10 / A N A L I Z A-D E S I T U A \% C 5 \% A 2 I E ~}$ -TUTUN.pdf

12. NOVEANU, L., BOJIN, F., FIRA-MLADINESCU, O., GHERBON, A., ANDOR, M., MIHALAŞ, G., Tendencies in smoking status and smoking habits among medical students during the first three years of medical studies. Physiology, 2009; 19(2):12-6.

13. *** WHO Europe. Health impact of tobacco control policies in line with the WHO Framework Convention on Tobacco Control (WHO FCTC)- 2016.

14. *** Global Adult Tobacco Survey, 2011. http://www.who.int/tobacco/surveillance/survey/gats/rou/en/ 15. GOȚIA, S.M., GOŢIA, S.R., GURBAN, C., Nutrition, coffee, alcohol consumption in students' life style. Palestrica of the third millennium-Civilization and sport, 14(1): 2013, 7-11.

16. GEORGESCU, MILICA., Agenţia Naţională Antidrog. Studii în domeniul drogurilor. Raport de cercetare. Volume 3, Issue 1. Studiul naţional în şcoli privind consumul de tutun, alcool şi droguri, ESPAD -2015.

www.ana.gov.ro/studii/ESPAD\%20.2015.pdf. 1 de tutun, alcool și droguriESPAD 20159/25/2016.

17. DOLL, R., PETO, R., BOREHAM, J., SUTHERLAND, I., Mortality in relation to smoking: 50 years observations on male British doctors. BMJ, 328(7455), 2004, 1519.

doi: 10.1136/bmj.38142.554479.AE 
18. NOVEANU, L., MUNTEAN, C., GHERBON, A., FIRA-MLADINESCU, C., MIHALAŞ, G., Studiul prevalenței și a caracteristicilor obiceiului de a fuma printre studenții la medicină. Journal of Hygiene and Public Health, 2005; 55(4):88-95.

19. TIUREAN, L., POPA, D., ROGOZEA, L., Smoking - a true public health issue. JMB, 2015; 2:912.

20. IOVANESCU, D., FRANDES, M., LUNGEANU, D., BURLEA, A., MIUTESCU, B.P., MIUTESCU, E., Diagnosis reliability of combined flexible sigmoidoscopy and fecal-immunochemical test in colorectal neoplasia screening, OncoTargets and Therapy, 2016; 9:6819-28.

21. SOFUOGLU, M., HERMAN, I.A., ROBINSON. C., WATERS, J.A., Cognitive Effects of Nicotine. Effects of Drug Abuse on the Human Nervous System, 2014; 367-85.

$\overline{\text { Manuscript received: } 812.2019}$ 